\title{
Diagnostic Approaches for Large Vessel Vasculitides
}

\author{
Albrecht Betrains 1,2 \\ Daniel Blockmans ${ }^{1,2}$ \\ 'Department of General Internal \\ Medicine, University Hospitals Leuven, \\ Leuven, Belgium; ${ }^{2}$ Department of \\ Microbiology, Immunology and \\ Transplantation, Laboratory of Clinical \\ Infectious and Inflammatory Disorders, \\ KU Leuven, Leuven, Belgium
}

\begin{abstract}
The large vessel vasculitides comprise giant cell arteritis (GCA), Takayasu arteritis (TAK), and chronic periaortitis. The diagnostic approach to these conditions involves the correct use and interpretation of clinical criteria, imaging techniques, and, in case of GCA, temporal artery biopsy. Ultrasound, magnetic resonance imaging (MRI), and computed tomography (CT) reveal a homogeneous, concentric, thickening of the arterial wall. MRI and CT may also reveal aneurysms and stenoses. 18F-Fluorodeoxyglucose (FDG)-PET shows increased FDG uptake of inflamed artery walls delineating increased metabolic activity. Ultrasound, FDG-PET, and MRI are the recommended imaging techniques in GCA and TAK. In patients with a high suspicion of GCA who present with visual disturbances, initiation of high-dose intravenous corticosteroids should not be delayed by imaging. Extracranial large vessel vasculitis may be confirmed by all three modalities, particularly by FDG-PET in case of atypical clinical pictures. In this article, we review the role of the GCA and TAK ACR classification criteria, temporal artery biopsy, conventional angiography, ultrasound, MRI, magnetic resonance angiography (MRA), CT angiography (CTA), and FDG-PET in the diagnostic approach of large vessel vasculitis.
\end{abstract}

Keywords: large vessel vasculitis, giant cell arteritis, Takayasu arteritis, periaortitis, PETscan, ultrasonography, temporal artery biopsy

\section{Introduction}

Based on the Chapel-Hill consensus conference classification of primary vasculitides, the large-vessel vasculitis (LVV) group comprises giant cell arteritis (GCA) and Takayasu arteritis (TAK). ${ }^{1}$ In addition, chronic periaortitis is a non-infectious disorder in which the aorta is inflamed and comprises idiopathic retroperitoneal fibrosis, inflammatory abdominal aortic aneurysm (without involvement of ureters) and perianeurysmal retroperitoneal fibrosis (with involvement of ureters). Chronic

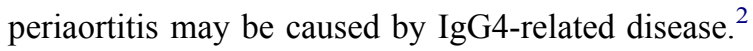

In the past, temporal artery biopsy has been regarded as the gold standard for diagnosis of GCA, and it still remains an important diagnostic tool for the cranial form of GCA today. ${ }^{3}$ More recently, temporal artery biopsy is increasingly being replaced by imaging techniques such as ultrasound and 18F-fluorodeoxyglucose positron emission tomography (FDG-PET), which are less invasive and may be more sensitive. ${ }^{4}$ In 2018 , Dejaco et al developed European League Against Rheumatism (EULAR) recommendations on the application of imaging for the diagnosis of $\mathrm{LVV}^{4}{ }^{4}$ These recommendations were based on both evidence and expert and patient consensus. They concluded that, from a patient's perspective, imaging is preferred over surgery. ${ }^{4}$ In addition, in
Correspondence: Daniel Blockmans Department of General Internal Medicine, University Hospitals Leuven, Herestraat 49 Leuven, 3000, Belgium

Tel +3216344279

Email daniel.blockmans@uzleuven.be 
case of suspected LVV, imaging results are directly available, whereas a temporal artery biopsy requires the patient to be treated based on suspicion prior to the availability of the biopsy results. ${ }^{4}$ The recommendations also suggested that, in patients in whom there is a high clinical suspicion of GCA, the diagnosis of GCA can be made based on a clearly positive ultrasound result without histology or additional imaging. ${ }^{4}$ In patients with extracranial LVV, FDG-PET, magnetic resonance imaging (MRI), and magnetic resonance angiography (MRA) play a central role in the diagnostic process. ${ }^{4}$ However, the EULAR recommendations also clearly emphasized that temporal artery biopsy should be performed in all cases where GCA could not be confirmed or excluded based on clinical, laboratory and imaging findings. ${ }^{4}$

This review article summarizes the role of history taking, physical examination, and laboratory testing, the GCA and TAK American College of Rheumatology classification criteria, temporal artery biopsy, conventional angiography, ultrasound, FDG-PET, computed tomography angiography (CTA), and MRI/MRA in the diagnostic approach of LVV.

\section{History Taking, Physical Examination, and Laboratory Testing}

The diagnostic approach to every patient with suspected LVV should include a comprehensive history, physical examination, and laboratory testing. No individual symptom, sign, or laboratory investigation result allows to establish a diagnosis of or rule out LVV, and additional imaging or temporal artery biopsy is typically required. ${ }^{5,6}$ While the symptoms of GCA, TAK, and chronic periaortitis may overlap to a certain degree, there are also some substantial differences. Clinical symptoms typically reflect end-organ ischemia, with the organs affected depending on the vessels that are involved, in addition to nonspecific symptoms related to systemic inflammation. ${ }^{7}$ With regard to the physical examination, all patients with suspected LVV should undergo thorough vascular examination including bilateral upper extremity blood pressure, cardiac auscultation, and assessment for vascular bruits or abnormal pulses in the carotid, temporal, and limb arteries, and signs of ischemia. Laboratory result abnormalities typically reflect an elevated acute-phase response, including high erythrocyte sedimentation rate and increased levels of C-reactive protein. ${ }^{8}$ However, this may be absent in patients with TAK. $^{9}$ A moderate, normochromic anemia may be present in individuals with active disease.
Van der Geest et al recently reported a systematic review and meta-analysis assessing the diagnostic accuracy of symptoms, signs, and laboratory findings in patients with GCA. ${ }^{5}$ They found a positive likelihood ratio (LR) of more than 2.00 only for a previous diagnosis of polymyalgia rheumatica (LR 2.07), jaw claudication (LR 4.90), and limb claudication (LR 6.01). Several symptoms that are considered typical of GCA, including temporal headache and transient vision loss, did not reach significance. ${ }^{5}$ With regard to the physical signs, a positive LR of more than 2.00 was found for most signs reflecting involvement of the temporal artery, including anterior ischemic optic neuropathy (LR 2.15), an abnormal temporal artery (LR 2.29), tenderness of the temporal area (LR 3.14 ), loss of pulse of the temporal artery (LR 3.25), and thickening of the temporal artery (LR 4.70). ${ }^{5}$ Concerning the laboratory testing, van der Geest et al found a positive LR for an erythrocyte sedimentation rate $(\mathrm{ESR})>60 \mathrm{~mm} / \mathrm{h}(\mathrm{LR}$ 2.40 ), $>80 \mathrm{~mm} / \mathrm{h}$ (LR 2.79), $>100 \mathrm{~mm} / \mathrm{h}$ (LR 3.11), and a platelet count $>400 \times 10^{9} / \mathrm{L}(\mathrm{LR} 3.75){ }^{5}$ The most important negative LR concerning the symptoms, signs, and laboratory results include being younger than 70 years (LR 0.48), an $\mathrm{ESR} \leq 40 \mathrm{~mm} / \mathrm{h}$ (LR 0.18), and a CRP lower than or equal to the reference value (LR 0.40;). ${ }^{5}$ While the findings by van der Geest et al need to be prospectively validated in the future, the authors provided a useful framework for the clinical approach to the diagnosis of suspected GCA. ${ }^{5}$

There is no systematic review assessing the accuracy of symptoms and signs in patients with TAK. However, Quinn et al reported on the clinical presentation of a large cohort of 275 TAK patients from the National Institutes of Health and the Vasculitis Clinical Research Consortium. ${ }^{10}$ They described five typical clinical presentation patterns, including patients with (1) vascular-related symptoms (46\%) encompassing limb claudication, cranial symptoms, angina, and abdominal claudication, (2) major ischemic events (29\%), (3) carotid artery tenderness $(15 \%)$, (4) nonspecific constitutional symptoms ( $8 \%)$, and (5) asymptomatic patients $(3 \%){ }^{10}$

Chronic periaortitis comprises idiopathic retroperitoneal fibrosis, inflammatory abdominal aorta aneurysms, and perianeurysmal retroperitoneal fibrosis. ${ }^{11}$ Patients with chronic periaortitis typically present with localized symptoms due to mass effect in the retroperitoneal space and systemic features secondary to systemic inflammation. ${ }^{11,12}$ The retroperitoneal mass effect can be associated with obstructive uropathy, lower limb edema, testicular manifestations, and constipation. ${ }^{11}$ Claudication or intestinal ischemia are less frequent. ${ }^{11}$ 


\section{American College of Rheumatology (ACR) Criteria}

Consensus criteria for classification of GCA have been described in 1990 by the ACR (Table 1A). ${ }^{13,14}$ The ACR classification criteria aimed to distinguish patients with different types of vasculitis to be included in clinical trials. $^{13}$ They were not intended to be used as a diagnostic tool in clinical practice. According to the ACR criteria, differentiation of GCA from other types of vasculitis requires 3 out of 5 criteria, which had a sensitivity of $93.5 \%$ and a specificity of $91.2 \%{ }^{13}$ However, it is very important to remember that these criteria cannot be used in a patient without evidence of vasculitis. ${ }^{13}$ In addition, they date from a time when GCA was considered to be limited to the cranial vessels and imaging techniques were not yet available except for angiography. ${ }^{15}$ Now we know that GCA frequently involves the large thoracic arteries, and we have new data for FDG-PET, MRI, and ultrasonography studies. ${ }^{4,15}$ Furthermore, several studies have indicated that the ACR criteria have poor specificity for GCA among patients with conditions mimicking GCA. ${ }^{16,17}$ The Diagnostic and Classification Criteria in Vasculitis Study (DCVAS) is an international observational study that aims to establish

Table I Summary of the American College of Rheumatology (ACR) Criteria for Giant Cell Arteritis (GCA) and Takayasu Disease (TAK)

\begin{tabular}{|c|c|}
\hline \multicolumn{2}{|c|}{ (A) ACR 1990 GCA Classification Criteria } \\
\hline Score & Criteria \\
\hline I & - Age at onset $\geq 50$ years \\
\hline I & - New headache \\
\hline I & $\begin{array}{l}\text { - Temporal artery abnormalities (tenderness to palpa- } \\
\text { tion, decreased pulsation) }\end{array}$ \\
\hline I & - $\mathrm{ESR} \geq 50 \mathrm{~mm} / \mathrm{h}$ \\
\hline I & $\begin{array}{l}\text { - Abnormal artery biopsy (vasculitis with mononuclear } \\
\text { cell or granulomatous inflammation, usually with } \\
\text { giant cell infiltrates) }\end{array}$ \\
\hline \multicolumn{2}{|c|}{ (B) ACR 1990 TAK classification criteria } \\
\hline Score & Criteria \\
\hline I & - Age at onset $\leq 40$ years \\
\hline 1 & - Extremity claudication \\
\hline 1 & - Decreased brachial artery pulse \\
\hline 1 & - Blood pressure difference $>10 \mathrm{mmHg}$ between arms \\
\hline 1 & - Bruit over subclavian arteries or aorta \\
\hline I & - Arteriogram abnormalities \\
\hline
\end{tabular}

a classification system and validate new diagnostic criteria for systemic vasculitis applying data-driven methods. ${ }^{18}$

In 1990, the ACR also published the consensus classification criteria for TAK (Table 1B). ${ }^{19}$ Classifying patients as TAK requires 3 out of 6 criteria, which has a sensitivity of $90.5 \%$ and specificity of $97.8 \% .{ }^{19}$ The main criticism about the ACR Criteria for TAK involves the age restriction criterion (disease onset $<40$ years) in addition to the fact that the control cohort used to develop the criteria included predominantly small vessel vasculitis patients but not patients with atherosclerotic disease or congenital aortic disorders. ${ }^{6}$ This limits the utility of the TAK ACR classification criteria in clinical practice.

\section{Temporal Artery Biopsy}

Transmural inflammation affecting the media has been the characteristic feature of a positive temporal artery biopsy (Figure 1). ${ }^{13,20}$ Fragmentation of the internal elastic lamina or the presence of multinucleated giant cells is not required. ${ }^{13,20}$ The significance of isolated (peri)adventitial inflammation remains to be determined. Galli et al recently reported on temporal artery inflammation limited to the (peri)adventitial tissue. ${ }^{21}$ They found that GCA or polymyalgia rheumatica was diagnosed in $86 \%$ of patients with inflammation limited to the adventitial or periadventitial tissue. However, this limited inflammation had a sensitivity of $41.9 \%$ and specificity of $52.5 \%$ for GCA. ${ }^{21}$

In a recent meta-analysis of reports on temporal artery biopsy results of GCA patients fulfilling the ACR criteria, the fraction of temporal artery biopsy-positive GCA cases was estimated to be $77 \% .^{22}$ However, there was high between-

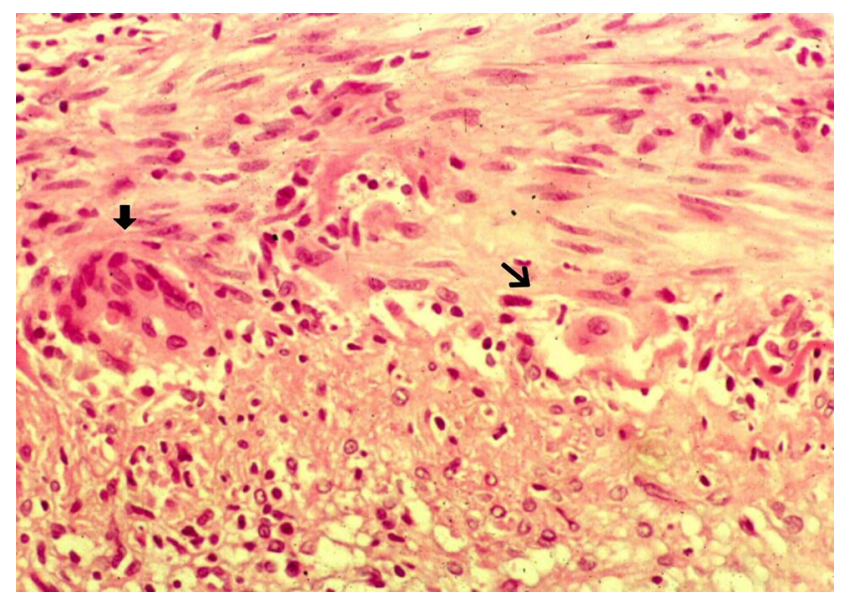

Figure I Positive temporal artery biopsy with fragmentation of the elastic internal lamina (arrow) on the junction between a hyperplastic intima (lower layer) and an inflamed media (upper layer) with the presence of multinucleated giant cells (block arrow). 
study heterogeneity with a sensitivity of $84 \%$ and $68 \%$ for reports published prior to 2012 and from 2012 on, respectively. $^{22}$ Accordingly, as stated by Ing et al, the pooled sensitivity reported by Rubinstein et al should be interpreted with caution. ${ }^{23}$ The decline over time in the percentage of temporal artery biopsy-positive GCA may correspond to an increase in temporal artery biopsy-negative GCA diagnosed based on PET-CT and other imaging modalities. ${ }^{22}$ In addition, growing evidence suggests that temporal artery biopsypositive and -negative GCA have distinctive features, corresponding to cranial and extracranial GCA, respectively. ${ }^{15}$

Biopsies suggestive of GCA tend to be longer compared to negative biopsies. ${ }^{24,25}$ A threshold length of $0.5-1.0 \mathrm{~cm}$ results in an increase of the diagnostic yield. ${ }^{24,25}$ However, the lack of biopsy procedure and processing methods standardization contributes to the variable sensitivity of temporal artery biopsy. Chu et al suggested an optimal biopsy prefixation length of 1.5-2.0 cm to diagnose patients with giant cell arteritis based on the analysis of 1190 temporal artery biopsies from 1163 patients. ${ }^{26}$ However, a recent study by Muratore et al found that a postfixation temporal artery biopsy specimen length of at least $5 \mathrm{~mm}$, corresponding to a prefixation surgical specimen length of $7-10 \mathrm{~mm}$, maximizes the diagnostic accuracy of temporal artery biopsy. ${ }^{27}$ They also reported that, in order not to miss inflammation limited to adventitial and/or periadventitial small vessels as described above, at least three other sections at deeper levels should be evaluated in all uninflamed temporal artery biopsy specimens. ${ }^{27}$ The TABUL study by Luqmani et al compared ultrasound to temporal artery biopsy in the diagnostic approach of GCA. ${ }^{28}$ The authors reported a lower sensitivity of the temporal artery biopsy compared to that of the ultrasound (39\% vs 54\%). ${ }^{28}$ Interestingly, they also reported a very moderate interoperator reproducibility between the different pathologists of $62 \%{ }^{28}$ As expected, a positive temporal artery biopsy result had a sensitivity approximating $100 \%{ }^{28}$

\section{Conventional Angiography}

Conventional angiography has often been considered to be the best diagnostic test for the diagnosis of TAK in the past (Figure 2). ${ }^{6}$ The International Conference on Takayasu Arteritis in 1994 classified the disease based on the angiographic findings. ${ }^{29}$ Due to the invasive nature of angiography and the impossibility of conducting a biopsy of large thoracic arteries, MRA, ultrasonography, and PET-CT are now widely used for the diagnosis of TAK. ${ }^{4}$ The role of conventional angiography has changed from a diagnostic tool to a treatment option with the implementation of endovascular interventions (dilatation and/or stenting of stenotic segments,

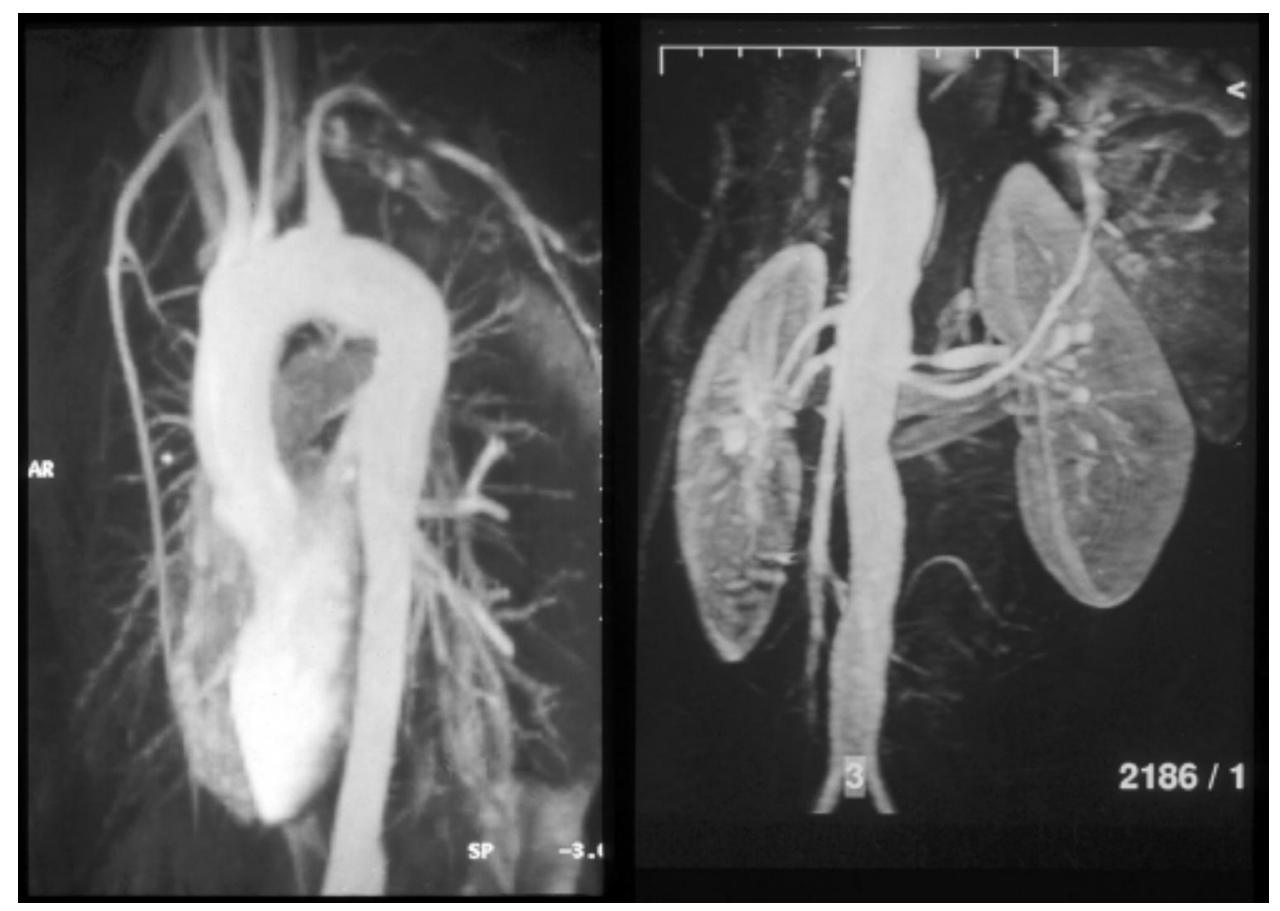

Figure 2 Conventional angiography in a 24-year-old woman with Takayasu disease (TAK) showing stenosis of the left subclavian artery, moderate dilatation of the entire thoracic aorta, irregular dilatation of the abdominal aorta, and stenosis of the left renal artery. 
endovascular prosthesis in case of aneurysm formation), which have improved the outcome of patients with $\mathrm{LVV}^{30,31}$

\section{Ultrasound}

\section{General Considerations}

Ultrasound is a technique that is widely available in clinical practice. It is less expensive compared to other imaging techniques and biopsy. Ultrasound of the unaffected temporal artery shows a compressible, pulsatile vessel with midto-hyperechoic tissue surrounding an anechoic lumen. ${ }^{32}$ The normal axillary artery is visualized as a pulsatile vessel with mid-to-hyperechoic tissue surrounding an anechoic lumen and is not easily compressible due to the deep anatomic location. ${ }^{32}$ For both structures, the intima-media complex can be identified with high resolution ultrasound equipment and is defined as a hypo- to anechoic structure surrounded by two aligned hyperechoic margins. ${ }^{32}$ In active vasculitis, inflammation of the artery results in a thickened vessel wall. ${ }^{33}$ On ultrasound, this is described as the halo sign (Figure 3), a hypoechoic vessel wall thickening that is clearly demarcated on the side of the vessel lumen and can be visualized in both the long and short axis. ${ }^{33}$ In addition, the hypoechoic vessel wall thickening surrounding the artery is typically incompressible. ${ }^{33}$ Artifacts associated with inadequate filling of the vessel lumen result in a deceptive "halo sign" but the artery remains compressible. ${ }^{33}$ Stenosis may result from severe wall thickening and is visible on Doppler ultrasound as a turbulent color pattern and persistent diastolic flow. ${ }^{33}$ Consideration of stenosis did not result in an increased sensitivity in a meta-analysis. ${ }^{34}$

A meta-analysis from 2018, only considering prospective reports including more than 20 patients with both GCA and TAK, showed a moderate sensitivity (77\% with $95 \%$ confidence interval $62-87 \%$ ), high specificity ( $96 \%$ with 95\% confidence interval $85-99 \%$ ), a positive LR of 19 , and a negative LR of $0.2 .{ }^{34}$ However, expertise and highquality equipment is essential to attain reliable findings with ultrasound. ${ }^{34}$ Unless a transesophageal echocardiography is performed, the main limitation of ultrasound remains the restricted ability to evaluate the thoracic aorta. ${ }^{34}$

\section{Ultrasound in GCA}

The standard ultrasound assessment comprises the temporal and axillary arteries. ${ }^{17}$ Examination of the femoral artery and popliteal artery is warranted if history and clinical examination indicate their involvement. ${ }^{35}$ In GCA, stenosis or occlusion of the axillary artery is associated with collateral blood flow in half of the cases. ${ }^{36}$ Ultrasound also allows assessment of extracranial arteries such as the common carotid artery, vertebral artery, and subclavian artery. ${ }^{37}$ However, as involvement of these structures in GCA is often associated with temporal artery or axillary artery vasculitis, routine assessment of these arteries with ultrasound does not result in a significantly increased sensitivity. ${ }^{37}$ With regard to examination of the aorta, in particular the descending thoracic aorta,

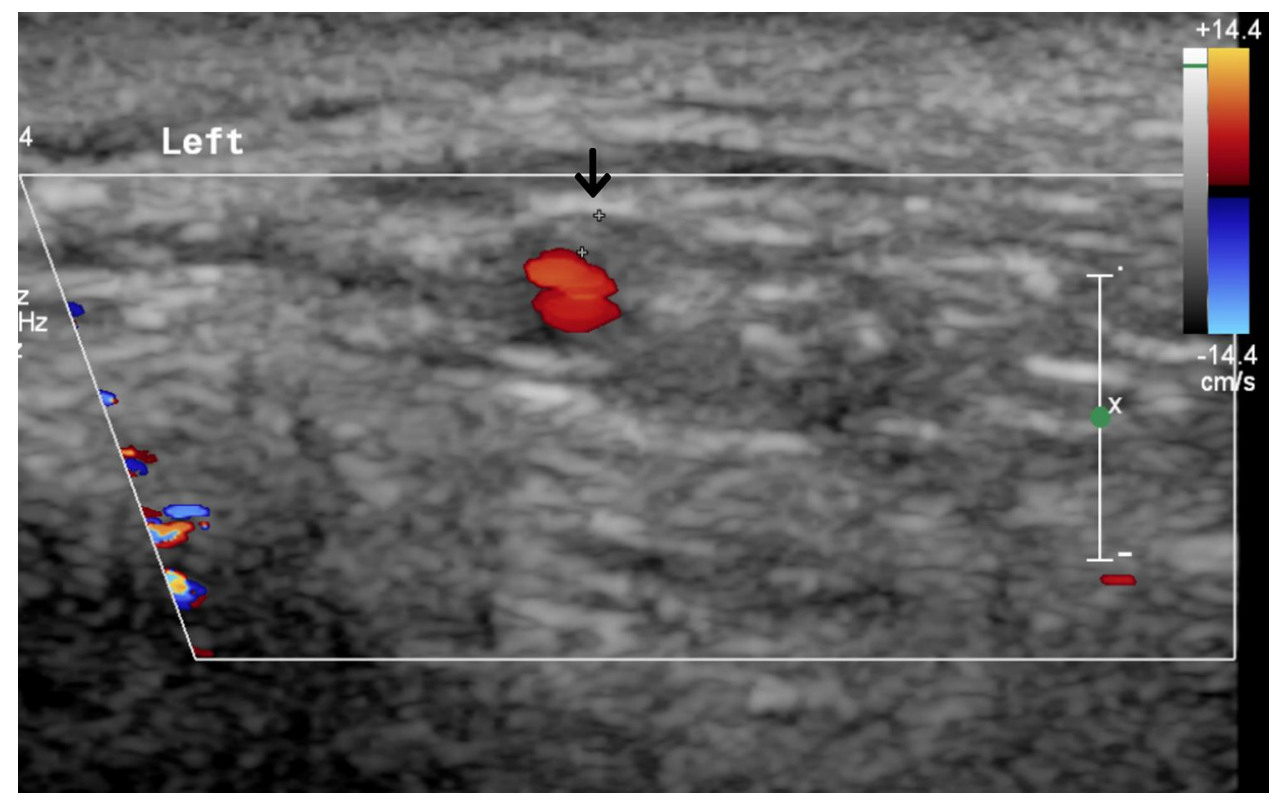

Figure 3 Cross-sectional Doppler ultrasound view of the left temporal artery in a 72-year-old patient with giant cell arteritis. The arrow shows the hypoechogenic halo sign. 
ultrasound has a clear disadvantage compared to CT, MRI, and PET. ${ }^{37}$ The abdominal aorta may be easier to visualize, but intestinal air and obesity may also impair visibility.

How temporal artery biopsy and ultrasound must be prioritized in the diagnostic approach of GCA remains indeterminate. In addition, when using biopsy-positive GCA cases as a reference, temporal artery ultrasound results were abnormal in $75 \%$ of cases at best. ${ }^{34,38,39}$ This implies that temporal artery biopsy and temporal artery ultrasound are not interchangeable, and that this non-invasive imaging technique cannot entirely substitute temporal artery biopsy. Furthermore, in a randomized study, Germano et al found no significant difference in the frequency of positive biopsy results in patients with suspected GCA between patients who underwent a color duplex sonography-guided biopsy and patients with a standard temporal artery biopsy. ${ }^{40}$ Thus, a color duplex sonography-guided approach does not increase the sensitivity of temporal artery biopsy in the diagnosis of GCA. ${ }^{40}$

Van der Geest et al developed a composite halo score, based on percentiles of halo thickness of the three temporal artery segments (common superficial, parietal, and frontal) and the axillary artery on each side at baseline in 89 patients with suspected GCA. ${ }^{17}$ The halo score has a decent sensitivity (78\%) but average specificity (55\%$61 \%$ ) for a diagnosis of GCA. ${ }^{17}$ However, the halo score has a fair ability to identify GCA patients at risk for ocular ischemia. ${ }^{17}$ Patients with a high halo score $(\geq 3)$ were at high risk $(>30 \%)$ of ocular ischemia, while patients with a low halo score showed a $\leq 5 \%$ risk of GCA-related vision loss. ${ }^{17}$ In another prospective study of 90 patients with suspected GCA, van der Geest et al found that the halo score could be useful to identify a subset of patients with GCA who have intimal hyperplasia [are under the curve $0.82(0.61-1.00)] .{ }^{41}$ GCA patients with intimal hyperplasia and a positive temporal artery biopsy result more frequently had ocular ischemia (40\%) compared to other patients with GCA $(14 \%){ }^{41}$

Ultrasound also plays an important role in fast-track pathways, which aim to ensure early referral, standardized assessment, and rapid treatment of patients with suspected GCA. $^{42,43}$ The early assessment includes temporal artery and axillary artery ultrasound in addition to temporal artery biopsy. ${ }^{42,43}$ Patil et al found that the fast-track pathway reduced permanent visual impairment in patients with GCA compared to the conventional approach in their center (OR $0.17 ; 95 \%$ CI $0.06-0.47 ; \mathrm{p}=0.001){ }^{42}$ Monti et al also found that a fast-track pathway including ultrasound assessment contributed to a reduced permanent vision loss risk in patients with GCA. ${ }^{43}$ However, the fast-track approach remains to be validated at other sites and in prospective studies.

\section{Ultrasound in TAK}

The standard ultrasound assessment in patients with TAK comprises the carotid, subclavian, and vertebral arteries in addition to the abdominal aorta, as these vessels are most commonly affected. ${ }^{9}$ The presence of arterial hypertension should prompt to examine the renal arteries. Ultrasound may show an increased wall thickness upon active disease. ${ }^{44}$ A meta-analysis found a pooled sensitivity of ultrasound for TAK of $81 \%$ (95\% CI: $69-89 \%$ ) compared to clinical criteria. $^{45}$ The pooled specificity was $100 \%{ }^{45}$ In addition, as stated by the authors, the extremely high specificity can also be explained by the case-control design of the studies included in the meta-analysis, which compared patients with longstanding TAK to healthy controls or patients with systemic lupus erythematosus. Thus, the specificity of US for TAK is likely overestimated substantially. ${ }^{45}$

Echocardiography may detect left ventricular hypertrophy due to a variety of causes, including renal hypertension, pulmonary hypertension, aortic valve insufficiency, and ascending aorta vasculitis. ${ }^{46}$

\section{Ultrasound in Chronic Periaortitis}

Contrast-enhanced ultrasound may identify periaortic changes on a microvascular level in inflammatory aortic diseases. The inflammatory process may lead to stenosis of the abdominal vasculature. ${ }^{47}$ On standard ultrasound, chronic periaortitis may also present as a hypoechoic mass encompassing the infrarenal aorta. ${ }^{47,48}$ Similar to GCA and TAK, aortitis is characterized on ultrasound by a thickened and hypoechoic artery. Enhancement with microbubble contrast can be seen within the wall of the artery with contrast-enhanced ultrasound. On contrastenhanced ultrasound imaging, an amplified enhancement of the periaortic tissue characterizing inflammation and hypervascularity of the adventitia may be detected. ${ }^{49}$

\section{Computed Tomography Angiography}

In LVV, CTA with contrast in the venous phase may detect arteritis as thickening of the vessel wall and enhancement with a double-ring pattern. ${ }^{50}$ In accordance with FDGPET, mural thickening of the aorta remains present in 
two out of three patients after one year of treatment with glucocorticoids, whereas the vessel wall contrast enhancement will disappear in most patients. ${ }^{51}$ In a prospective study on CTA performed in 25 patients with suspected GCA, and 15 who were ultimately diagnosed with GCA, mural thickening had a lower specificity ( $84.6 \%$ vs $100 \%)$ compared to an increased FDG-uptake on PET-scan with similar results regarding sensitivity $(73.3 \%$ vs $66.7 \%) .{ }^{52}$ Two concordance studies between CTA and PET/CT concluded that both techniques are able to identify involvement of the large vessels in GCA. ${ }^{53,54}$ However, PET/CT was more performant to detect inflammation of the aortic branches. ${ }^{53}$ Serial CT imaging of the aorta may detect aortic structural damage, including late aortic dilatation, which may affect one in three patients after long-term follow-up. $^{55}$ Furthermore, CT angiography is a comprehensive technique for vascular evaluation in TAK patients. It allows evaluation of both the vessel lumen and vessel wall changes, of which the latter may precede the vascular remodeling. ${ }^{56-58}$

\section{MRI Imaging General Considerations}

MRI is becoming widely available for the workup of extracranial LVV. ${ }^{4}$ Less frequently, MRI is used to examine the temporal and occipital arteries. ${ }^{59}$ MRA may provide a comprehensive overview of all affected arteries in LVV. It is also superior to ultrasound for the detection of periaortitis. ${ }^{59} \mathrm{LVV}$ is shown on MRI as concentric wall thickening with mural contrast enhancement and edema of the artery wall on T2-weighted images. ${ }^{60}$ To detect inflammation of the vessel wall early in the disease course, postcontrast T2-weighted images are superior when compared to regular T2-weighted images. ${ }^{60}$ MRA also allows evaluation of the artery lumen for stenosis, occlusion, or aneurysm formation. ${ }^{60,61}$

\section{MRI in Giant Cell Arteritis}

A pooled analysis of six studies involving 509 patients comparing MRI with the clinical diagnosis of GCA as a reference found a sensitivity of $73 \%$ (95\% CI 57-85\%) and a specificity of $88 \%$ (95\% CI 81-92\%) with a positive LR of 5.9 (95\% CI 3.4-10.3) and a negative LR of 0.3 $(0.2-0.5) .{ }^{34}$ A pooled analysis of six reports with a total of 443 cases comparing MRI of the cranial arteries with temporary artery biopsy found a sensitivity of 93\% (95\% CI $89-96 \%)$ and a specificity of $81 \%$ (95\% CI $73-87 \%)$ with a positive LR of 5.0 (95\% CI 3.2-7.8) and a negative LR of $0.1(0.1-0.1){ }^{34}$ In addition to involvement of the extra-cerebral arteries, intra-cerebral vasculitis may be detected, but this does not increase the sensitivity. ${ }^{59,62,63}$

\section{MRI in Takayasu Arteritis}

To establish the diagnosis of TAK, EULAR indicates MRI as the preferred imaging technique, which allows to assess both the artery wall and the lumen. ${ }^{4}$ It also provides an entire overview of all significant arteries (Figure 4). MRI has a sensitivity of $98 \%$ and a specificity of $100 \%$ for TAK when compared to angiography as a reference. ${ }^{64}$ This was also confirmed in a meta-analysis of smaller studies evaluating MRI in TAK, which reported a sensitivity and specificity of more than $90 \%{ }^{45}$

\section{MRI in Chronic Periaortitis}

In chronic periaortitis with retroperitoneal fibrosis, MRI is superior in providing delineation between the inflammation and the surrounding tissue when compared to ultrasound and $\mathrm{CT}^{65}$ Retroperitoneal fibrosis may be visualized as hypointense in T1-weighted images and hyperintense during the active phase in T2-weighted images. ${ }^{65}$ The hyperintensity in the early phase is due to edema and hypercellularity, evolving to a lower intensity in the later stages. ${ }^{59,65}$ MRI may also

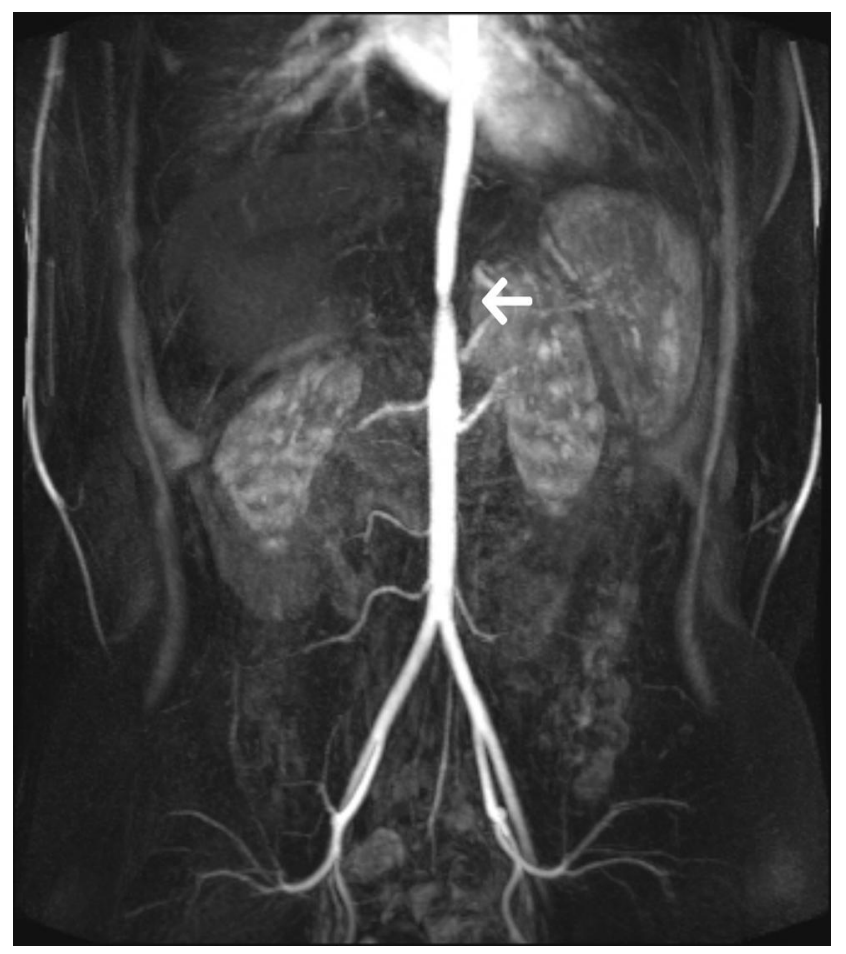

Figure $4 \mathrm{MR}$ angiography showing aortic stenosis (arrow) at the thoracoabdominal transition in a 20 -year-old patient with Takayasu disease. 
reliably differentiate retroperitoneal fibrosis from malignant neoplasm and lymphoma. ${ }^{66,67}$

\section{PET Imaging}

\section{General Considerations}

FDG-PET is a scintigraphic technique used to diagnose and assess LVV. FDG-PET is often combined with CT. In addition, FDG-PET/MRI is more recently being introduced. Transport of FDG across capillaries correlates with glucose uptake. Malignant cells have an increased glucose metabolism when compared to normal cells, explaining the important role of FDG-PET in hematology and oncology. Activated white blood cells also have an increased glucose metabolism, hence the frequent use of FDG-PET in infections and non-infectious inflammatory disorders. It provides functional information on the metabolic activity of organs and structures. Table 2 provides an overview and comparison of the diagnostic examinations used in patients with large vessel vasculitis. ${ }^{68}$

\section{FDG-PET in GCA}

FDG-PET may visualize inflammation of the larger arteries in patients with extracranial GCA, in whom the temporal artery is spared but there is involvement of the aorta and its branches (Figure 5). PET-CT is the best imaging examination in case of an atypical clinical presentation with a broad differential diagnosis, as it is a very effective imaging technique to identify LVV when it is unexpected. ${ }^{61}$ Detection of temporal artery inflammation was considered impossible on PET-CT because of the anatomical location next to the FDG consuming brain, their superficial location, and small vessel diameter. However, more recently, visualization of temporal artery inflammation has been reported on the newest PET-CT engines and is also correlating with cranial symptoms and histological findings compatible with GCA. ${ }^{69,70}$ FDGuptake of the larger arteries is very specific for vasculitis, but atherosclerosis may complicate the interpretation of PET-CT images. Vasculitis is shown as a linear, smooth FDG-uptake, in contrast to atherosclerosis which has a spotty appearance, corresponding to the atherosclerotic plaques. FDG-uptake of the thoracic aorta and its main branches has a very high specificity of $95 \%$ to $100 \%$ for vasculitis. The specificity decreases to $70 \%$ to $80 \%$ when only the abdominal aorta or lower limb arteries are considered, because these vessels are more disposed to atherosclerosis. In GCA, symmetrical FDG-uptake is typically noted, and the arteries are bilaterally affected in equal measure. The vessels that are most frequently affected include the subclavian arteries $(75 \%)$, the thoracic and abdominal aorta (50\%), and the axillary, carotid, iliac, and femoral arteries (30-40\%). ${ }^{71}$ When GCA is suspected, PET-CT should be performed as soon as possible. The sensitivity and specificity of PET-CT decreases after initiating treatment and up to $50 \%$ of PET-CT may become negative after 10 days. $^{72,73}$ Performing the PET-CT imaging within 3 days after oral glucocorticoid initiation is warranted. Moreover, there are no data on the sensitivity and specificity of PET-CT after 3 days of high-dose intravenous corticosteroid administration, which is required in case of visual disturbances.

Patients with GCA have an increased risk of developing thoracic aortic aneurysms. ${ }^{74}$ In a retrospective study of 46 patients with GCA, patients with an increased aortic FDG-uptake at diagnosis had a significantly increased diameter of the ascending and descending aorta compared to patients without aortic FDG-uptake at a mean of $3.9 \pm 2.5$ years after diagnosis, with FDG-uptake being the only independent variable for the volume of the thoracic aorta $(p=.039)$ in multivariate analysis. ${ }^{75}$ In a multicenter cohort study, a positive PET scan at diagnosis was the only parameter which correlated significantly with aortic complications that occurred in 9 out of 130 patients with GCA. ${ }^{76}$ In a cohort study of 93 patients with LVV, patients with GCA who had significant aortic FDG- uptake (grade 3) at their initial PET-CT were at increased risk of aortic dilatation. ${ }^{77}$ These studies conclude that patients with GCA who have a high aortic FDGuptake at diagnosis are more likely to develop aortic dilatation during follow-up. If this would be confirmed in a prospective study, PET-CT should probably be performed in every patient with GCA at diagnosis, to evaluate the risk of late aneurysm formation.

\section{PET in TAK}

Several studies have investigated the utility of PET in patients with TAK. ${ }^{78-82}$ PET-CT may aid substantially in establishing an early diagnosis and assess disease activity in TAK patients. ${ }^{45}$ A meta-analysis of imaging modalities found a combined sensitivity of $81 \%$ (95\% CI 69-89\%) and specificity of $74 \%(95 \%$ CI $55-86 \%) .{ }^{45}$ The performance of PET was not significantly different when PET was performed alone in comparison to PET combined with CT or CTA. ${ }^{45}$ Active disease detected by PET, alone or in combination with CT or CTA, was also associated with an 
Table 2 Comparison of Diagnostic Examinations in Patients with Large Vessel Vasculitis

\begin{tabular}{|c|c|c|c|}
\hline Imaging Technique & Assessment & Advantages & Limitations \\
\hline Temporal artery biopsy & - Histology & $\begin{array}{l}\text { - Histological diagnosis of temporal } \\
\text { arteritis }\end{array}$ & $\begin{array}{l}\text { - Invasive } \\
\text { - Result not immediately available } \\
\text { - Local complications } \\
\text { - Skip lesions }\end{array}$ \\
\hline $\begin{array}{l}\text { Conventional } \\
\text { angiography }\end{array}$ & - Lumen & $\begin{array}{l}\text { - Comprehensive vascular evaluation } \\
\text { possible } \\
\text { - High resolution for small vessels } \\
\text { - Therapeutic intervention }\end{array}$ & $\begin{array}{l}\text { - Radiation } \\
\text { - Invasive } \\
\text { - Contraindication for contrast in case of } \\
\text { iodine allergy } \\
\text { - Contraindication for contrast in case of } \\
\text { renal impairment }\end{array}$ \\
\hline Ultrasound & $\begin{array}{l}\text { - Lumen } \\
\text { - Wall thickening (halo) }\end{array}$ & $\begin{array}{l}\text { - Inexpensive } \\
\text { - No radiation } \\
\text { - No contrast/venipuncture needed } \\
\text { - Good resolution for medium and small } \\
\text { arteries } \\
\text { - - Microbubble contrast for increased } \\
\text { resolution of vessel wall }\end{array}$ & $\begin{array}{l}\text { - Long assessment time for comprehen- } \\
\text { sive vascular assessment } \\
\text { - Interobserver variation } \\
\text { - Not suitable for structures below air } \\
\text { or bone }\end{array}$ \\
\hline CT/CTA & $\begin{array}{ll}\text { - } & \text { Lumen } \\
\text { - Wall thickening } \\
\text { - } & \text { Contrast enhancement } \\
\text { - } & \text { Vessel diameter }\end{array}$ & $\begin{array}{l}\text { - Comprehensive vascular evaluation } \\
\text { possible } \\
\text { - Minimally invasive } \\
\text { - Cost reasonable }\end{array}$ & $\begin{array}{l}\text { - Radiation } \\
\text { - Venipuncture } \\
\text { - Limited resolution for small vessels } \\
\text { - Contraindication for contrast in case of } \\
\text { iodine allergy } \\
\text { - Contraindication for contrast in case of } \\
\text { renal impairment }\end{array}$ \\
\hline MRI/MRA & $\begin{array}{l}\text { - Lumen } \\
\text { - Wall thickening } \\
\text { - Contrast enhancement } \\
\text { - Vessel diameter } \\
\text { - Wall edema }\end{array}$ & $\begin{array}{l}\text { - Comprehensive vascular evaluation } \\
\text { - Mossible } \\
\text { - Minimally invasive } \\
\text { - No radiation }\end{array}$ & $\begin{array}{l}\text { - Long acquisition time } \\
\text { - Venipuncture } \\
\text { - Limited resolution for small vessels } \\
\text { - Expensive } \\
\text { - Contraindication for contrast in case of } \\
\text { renal impairment } \\
\text { - Claustrophobia } \\
\text { - Not feasible with some metal devices }\end{array}$ \\
\hline $\begin{array}{l}\text { PET (usually combined } \\
\text { with CT or MRI) }\end{array}$ & 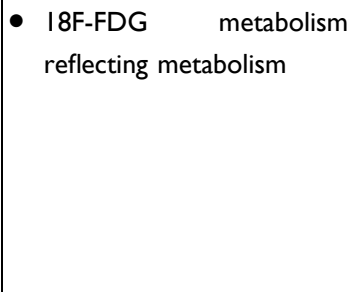 & $\begin{array}{l}\text { - Comprehensive vascular evaluation } \\
\text { possible } \\
\text { - Minimally invasive } \\
\text { - Whole-body assessment }\end{array}$ & $\begin{array}{l}\text { - Radiation } \\
\text { - Venipuncture } \\
\text { - No standards for positivity (FDG } \\
\text { uptake) } \\
\text { - No or limited resolution for small } \\
\text { vessels } \\
\text { - Not widely available }\end{array}$ \\
\hline
\end{tabular}

Note: Adapted from Rheum Dis Clin North Am, 42(4), Prieto-González S, Espígol-Frigolé G, García-Martínez A, et al. The expanding role of imaging in systemic vasculitis. 733751, Copyright (2016), with permission from Elsevier. ${ }^{68}$

acute phase response with a pooled odds ratio of 3.7 for ESR and an odds ratio of 4.1 for CRP. ${ }^{45}$ Follow-up PET data of a limited number of studies showed improvement of the PET abnormalities following treatment in some but not all studies. ${ }^{81,82}$ In only two studies, the improvement of the PET findings was in accordance with the clinical activity. ${ }^{81,82}$ Caution is warranted when arterial grafts are present, as they can cause confusion. ${ }^{83}$

\section{PET in Chronic Periaortitis}

In patients with chronic periaortitis, increased FDG-uptake is often noted encompassing the aorta. ${ }^{84-88}$ PET-CT may 


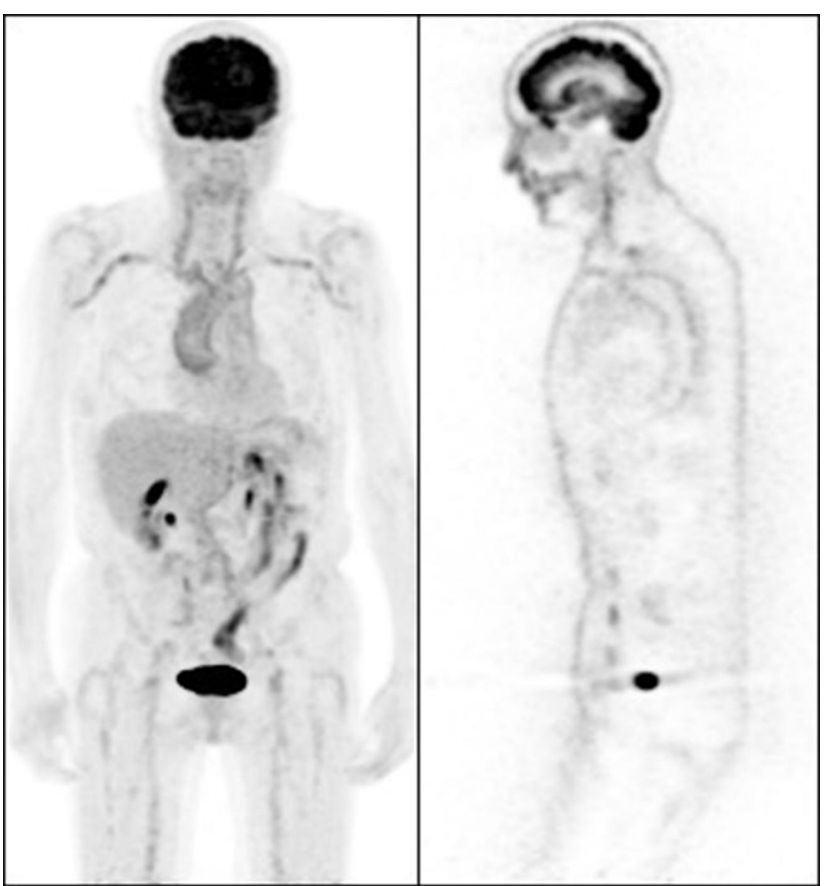

Figure 5 FDG-PET in an 8I-year-old patient with temporal artery biopsy-positive giant cell arteritis. Increased FDG-uptake is apparent in the ascending and descending thoracic aorta, the subclavian arteries, the axillary arteries, the carotid arteries, the iliac arteries, and the femoral arteries.

also detect other affected organs when the periaortitis is part of a systemic disorder, including IgG4-related disease or Erdheim-Chester disease. ${ }^{89-92}$

\section{Conclusion}

In patients with a high suspicion of GCA who present with visual disturbances, initiation of high-dose intravenous corticosteroids should not be delayed by imaging techniques. In these patients, temporal artery ultrasound performed by an experienced technician or temporal artery biopsy are probably the two preferred modalities. In patients with suspected GCA who present with typical manifestations, including headache and jaw claudication, PET-CT, ultrasound, and temporal artery biopsy may be considered depending on the local options and expertise. Corticosteroids can be started once the diagnosis is confirmed or a biopsy is obtained. In patients with suspected TAK, MRI and PET-CT are the best imaging techniques to detect mural inflammation or luminal changes to support the diagnosis. In young patients with TAK, MRI may be preferred to limit radiation exposure. PET-CT should be considered as a first-line imaging modality in patients with chronic periaortitis and may aid in detecting other affected organs when the periaortitis is part of a systemic disorder. In these patients, MRI is excellent to differentiate the inflammation from the surrounding tissues.
Combined PET-MRI engines are becoming available and may become the standard imaging procedure in LVV in future. Finally, in patients presenting with atypical clinical pictures, such as fever, weight loss, or isolated elevation of inflammatory markers, PET-CT has been shown to be the most effective imaging modality.

\section{Disclosure}

The authors report no conflicts of interest in this work.

\section{References}

1. Jennette J, Falk R, Bacon P, et al. 2012 revised international chapel hill consensus conference nomenclature of vasculitides. Arthritis Rheum. 2013;65(1):1-11. doi:10.1002/art.37715

2. Castelein T, Coudyzer W, Blockmans D. IgG4-related periaortitis vs idiopathic periaortitis: is there a role for atherosclerotic plaque in the pathogenesis of IgG4-related periaortitis? Rheumatology (Oxford). 2015;54(7):1250-1256.

3. Hall S, Lie JT, Kurland LT, Persellin S, O'Brien PC, Hunder GG. The therapeutic impact of temporal artery biopsy. Lancet. 1983;322 (8361):1217-1220.

4. Dejaco C, Ramiro S, Duftner C, et al. EULAR recommendations for the use of imaging in large vessel vasculitis in clinical practice. Ann Rheum Dis. 2018;77(5):636-643.

5. van der Geest KSM, Sandovici M, Brouwer E, Mackie SL. Diagnostic accuracy of symptoms, physical signs, and laboratory tests for giant cell arteritis: a systematic review and meta-analysis. JAMA Intern Med. 2020;180(10):1295-1304.

6. Kim ESH, Beckman J. Takayasu arteritis: challenges in diagnosis and management. Heart. 2018;104(7):558-565.

7. Weyand CM, Goronzy JJ. Medium-and large-vessel vasculitis. N Engl J Med. 2003;349(2):160-169.

8. Weyand CM, Goronzy JJ. Giant-cell arteritis and polymyalgia rheumatica. $N$ Engl $J$ Med. 2014;371(1):50-57. doi:10.1056/ NEJMcp 1214825

9. Kerr GS, Hallahan CW, Giordano J, et al. Takayasu arteritis. Ann Intern Med. 1994;120(11):919-929.

10. Quinn KA, Gribbons KB, Carette S, et al. Patterns of clinical presentation in Takayasu's arteritis. Semin Arthritis Rheum. 2020;50 (4):576-581. doi:10.1016/j.semarthrit.2020.04.012

11. Marvisi C, Buttini EA, Vaglio A Aortitis and periaortitis: the puzzling spectrum of inflammatory aortic diseases. Presse Med 2020:104018.

12. Vaglio A, Salvarani C, Buzio C. Retroperitoneal fibrosis. Lancet. 2006;367(9506):241-251. doi:10.1016/S0140-6736(06)68035-5

13. Hunder GG, Bloch DA, Michel BA, et al. The American College of Rheumatology 1990 criteria for the classification of giant cell arteritis. Arthritis Rheum. 2010;33(8):1122-1128. doi:10.1002/ art. 1780330810

14. Tuckwell K, Collinson N, Klearman M, Dimonaco S, Stone JH, Investigators $\mathrm{G}$. Classification criteria for giant cell arteritis: data from giacta informing the need for revision. Ann Rheum Dis. 2016;75:571.

15. de Boysson H, Liozon E, Ly KH, Dumont A, Delmas C, Aouba A. The different clinical patterns of giant cell arteritis. Clin Exp Rheumatol. 2019;37 Suppl 1(2):57-60.

16. Seeliger B, Sznajd J, Robson JC, et al. Are the 1990 American College of Rheumatology vasculitis classification criteria still valid? Rheumatology (Oxford). 2017;56(7):1154-1161.

17. Ksm VDG, Borg F, Kayani A, et al. Novel ultrasonographic Halo Score for giant cell arteritis: assessment of diagnostic accuracy and association with ocular ischaemia. Ann Rheum Dis. 2020;79 (3):393-399. 
18. Ponte C, Grayson PC, Suppiah R, et al. Development of the Classification Criteria for GIANT Cell Arteritis in the Diagnostic and Classification Criteria for Vasculitis Study: a Pilot Study Using A Panel Review Methodology. Ann Rheum Dis. 2014;73(2):555.

19. Aws DS, de Carvalho JF. Diagnostic and classification criteria of Takayasu arteritis. J Autoimmun. 2014;48:79-83.

20. Jennette JC, Falk RJ. The role of pathology in the diagnosis of systemic vasculitis. Clin Exp Rheumatol. 2007;25(1 Suppl 44):S52-6.

21. Galli E, Muratore F, Boiardi L, et al. Significance of inflammation restricted to adventitial/periadventitial tissue on temporal artery biopsy. Semin Arthritis Rheum. 2020;50:1064-1072.

22. Rubenstein E, Maldini C, Gonzalez-Chiappe S, Chevret S, Mahr A. Sensitivity of temporal artery biopsy in the diagnosis of giant cell arteritis: a systematic literature review and meta-analysis. Rheumatology. 2020;59(5):1011-1020.

23. Ing EB, Wang DN, Kirubarajan A, et al. Systematic review of the yield of temporal artery biopsy for suspected giant cell arteritis. Neuroophthalmology. 2019;43(1):18-25.

24. Taylor-Gjevre R, Vo M, Shukla D, Resch L. Temporal artery biopsy for giant cell arteritis. J Rheumatol. 2005;32(7):1279-1282.

25. Mahr A, Saba M, Kambouchner M, et al. Temporal artery biopsy for diagnosing giant cell arteritis: the longer, the better? Ann Rheum Dis. 2006;65(6):826-828.

26. Chu R, Foster C, Ali M, et al. Optimal length and usefulness of temporal artery biopsies in the diagnosis of giant cell arteritis: a 10 -year retrospective review of medical records. Lancet Rheumatol. 2020;2(12):e774-e778.

27. Muratore F, Boiardi L, Cavazza A, et al. Association between specimen length and number of sections and diagnostic yield of temporal artery biopsy for giant cell arteritis. Arthritis Care Res (Hoboken). 2021;73(3):402-408.

28. Luqmani R, Lee E, Singh S, et al. The and Treatment role of ultrasound compared to biopsy of temporal arteries in the diagnosis of Giant Cell Arteritis (TABUL): a diagnostic accuracy and cost-effectiveness study. Health Technol Assess. 2016;20(90):1-238.

29. Jennette JC, Falk RJ, Andrassy K, et al. Nomenclature of systemic vasculitides. Arthritis Rheum. 1994;37(2):187-192.

30. Saadoun D, Lambert M, Mirault T, et al. Retrospective analysis of surgery versus endovascular intervention in Takayasu arteritis: a multicenter experience. Circulation. 2012;125(6):813-819.

31. Baril DT, Carroccio A, Palchik E, et al. Endovascular treatment of complicated aortic aneurysms in patients with underlying arteriopathies. Ann Vasc Surg. 2006;20(4):464-471.

32. Chrysidis S, Duftner C, Dejaco C, et al. Definitions and reliability assessment of elementary ultrasound lesions in giant cell arteritis: a study from the OMERACT Large Vessel Vasculitis Ultrasound Working Group. RMD Open. 2018;4(1):e000598.

33. Schmidt W, Kraft H, Völker L, Vorpahl K, Colour G-IE. Doppler sonography to diagnose temporal arteritis. Lancet. 1995;345(8953):866.

34. Duftner C, Dejaco C, Sepriano A, Falzon L, Schmidt WA, Ramiro S. Imaging in diagnosis, outcome prediction and monitoring of large vessel vasculitis: a systematic literature review and meta-analysis informing the EULAR recommendations. RMD Open. 2018;4(1):e000612.

35. Schmidt WA. Ultrasound in the diagnosis and management of giant cell arteritis. Rheumatology. 2018;57(suppl_2):ii22-ii31.

36. Schmidt WA, Seifert A, Gromnica-ihle E, Krause A, Natusch A. Ultrasound of proximal upper extremity arteries to increase the diagnostic yield in large-vessel giant cell arteritis. Rheumatology. 2008;47 (1):96-101.

37. Schmidt WA, Blockmans D. Investigations in systemic vasculitis the role of imaging. Best Pract Res Clin Rheumatol. 2018;32 (1):63-82.

38. Rinagel M, Chatelus E, Jousse-Joulin S, et al. Diagnostic performance of temporal artery ultrasound for the diagnosis of giant cell arteritis: a systematic review and meta-analysis of the literature. Autoimmun Rev. 2019;18(1):56-61.
39. Karassa FB, Matsagas MI, Schmidt WA, Ioannidis JPA. Metaanalysis: test performance of ultrasonography for giant-cell arteritis. Ann Intern Med. 2005;142(5):359-369.

40. Germanò G, Muratore F, Cimino L, et al. Is colour duplex sonography-guided temporal artery biopsy useful in the diagnosis of giant cell arteritis? A randomized study. Rheumatology. 2015;54 (3):400-404.

41. van der Geest KSM, Wolfe K, Borg F, et al. Ultrasonographic Halo Score in giant cell arteritis: association with intimal hyperplasia and ischaemic sight loss. Rheumatology. 2020.

42. Patil P, Williams M, Maw WW, et al. Fast track pathway reduces sight loss in giant cell arteritis: results of a longitudinal observational cohort study. Clin Exp Rheumatol. 2015;33(2 Suppl 89):S-103-6.

43. Monti S, Bartoletti A, Bellis E, Delvino P, Montecucco C. Fast-track ultrasound clinic for the diagnosis of giant cell arteritis changes the prognosis of the disease but not the risk of future relapse. Front Med. 2020;7:589794.

44. Fan W, Zhu J, Li J, Zhang W, Li C. Ultrasound morphological changes in the carotid wall of Takayasu's arteritis: monitor of disease progression. Int Angiol. 2016;35(6):586-592.

45. Barra L, Kanji T, Malette J, Pagnoux C. Imaging modalities for the diagnosis and disease activity assessment of Takayasu's arteritis: a systematic review and meta-analysis. Autoimmun Rev. 2018;17 (2): $175-187$.

46. Schmidt WA. Role of ultrasound in the understanding and management of vasculitis. Ther Adv Musculoskelet Dis. 2014;6(2):39-47.

47. Czihal M, Lottspeich C, Hoffmann U. Ultrasound imaging in the diagnosis of large vessel vasculitis. Vasa. 2017;46(4):241-253.

48. Partovi S, Imfeld S, Aschwanden M, Bilecen D, Jaeger KA, Staub D. The use of contrast-enhanced ultrasound (CEUS) in chronic periaortitis. Ultraschall der Medizin-European $J$ Ultrasound. 2013;34(01):2-3.

49. Li X, Staub D, Rafailidis V, Al-Natour M, Kalva S, Partovi S. Contrast-enhanced ultrasound of the abdominal aorta-current status and future perspectives. Vasa. 2019;48:115-125.

50. Prieto-González S, Arguis P, García-Martínez A, et al. Large vessel involvement in biopsy-proven giant cell arteritis: prospective study in 40 newly diagnosed patients using CT angiography. Ann Rheum Dis. 2012;71(7):1170-1176.

51. Prieto-González S, García-Martínez A, Tavera-Bahillo I, et al. Effect of glucocorticoid treatment on computed tomography angiography detected large-vessel inflammation in giant-cell arteritis. A prospective, longitudinal study. Medicine (Baltimore). 2015;94:5.

52. Lariviere D, Benali K, Coustet B, et al. Positron emission tomography and computed tomography angiography for the diagnosis of giant cell arteritis: a real-life prospective study. Medicine (Baltimore). 2016;95:30.

53. De Boysson H, Dumont A, Liozon E, et al. Giant-cell arteritis: concordance study between aortic CT angiography and FDG-PET/ $\mathrm{CT}$ in detection of large-vessel involvement. Eur J Nucl Med Mol Imaging. 2017;44(13):2274-2279.

54. Hommada M, Mekinian A, Brillet P-Y, et al. Aortitis in giant cell arteritis: diagnosis with FDG PET/CT and agreement with CT angiography. Autoimmun Rev. 2017;16(11):1131-1137.

55. García-Martínez A, Arguis P, Prieto-González S, et al. Prospective long term follow-up of a cohort of patients with giant cell arteritis screened for aortic structural damage (aneurysm or dilatation). Ann Rheum Dis. 2014;73(10):1826-1832.

56. Park JH, Chung JW, Lee KW, Park YB, Han MC. CT angiography of Takayasu arteritis: comparison with conventional angiography. $J$ Vasc Interv Radiol. 1997;8(3):393-400.

57. Zhu FP, Luo S, Wang ZJ, Jin ZY, Zhang LJ, Lu GM. Takayasu arteritis: imaging spectrum at multidetector $\mathrm{CT}$ angiography. $\mathrm{Br}$ J Radiol. 2012;85(1020):e1282-e1292.

58. Khandelwal N, Kalra N, Garg MK, et al. Multidetector CT angiography in Takayasu arteritis. Eur J Radiol. 2011;77(2):369-374. 
59. Siemonsen S, Brekenfeld C, Holst B, Kaufmann-Buehler A-K, Fiehler J, Bley TA. 3T MRI reveals extra-and intracranial involvement in giant cell arteritis. Am J Neuroradiol. 2015;36(1):91-97.

60. Muratore F, Pipitone N, Salvarani C, Schmidt WA. Imaging of vasculitis: state of the art. Best Pract Res Clin Rheumatol. 2016;30 (4):688-706.

61. Blockmans D, Luqmani R, Spaggiari L, Salvarani C. Magnetic resonance angiography versus $18 \mathrm{~F}$-fluorodeoxyglucose positron emission tomography in large vessel vasculitis. Autoimmun Rev. 2019;18 (12): 102405

62. Bley TA, Wieben O, Uhl M, Thiel J, Schmidt D, Langer M. Highresolution MRI in giant cell arteritis: imaging of the wall of the superficial temporal artery. Am J Roentgenol. 2005;184(1):283-287.

63. Bley TA, Weiben O, Uhl M, et al. Assessment of the cranial involvement pattern of giant cell arteritis with 3T magnetic resonance imaging. Arthritis Rheum. 2005;52(8):2470-2477.

64. Yamada I, Nakagawa T, Himeno Y, Kobayashi Y, Numano F, Shibuya H. Takayasu arteritis: diagnosis with breath-hold contrastenhanced three-dimensional MR angiography. J Magn Reson Imaging. 2000;11(5):481-487.

65. Kamper L, Brandt AS, Ekamp H, et al. Diffusion-weighted MRI findings of treated and untreated retroperitoneal fibrosis. Diagnostic Interv Radiol. 2014;20(6):459.

66. Bakir B, Yilmaz F, Turkay R, et al. Role of diffusion-weighted MR imaging in the differentiation of benign retroperitoneal fibrosis from malignant neoplasm: preliminary study. Radiology. 2014;272 (2):438-445.

67. Rosenkrantz AB, Spieler B, Seuss CR, Stifelman MD, Kim S. Utility of MRI features for differentiation of retroperitoneal fibrosis and lymphoma. Am J Roentgenol. 2012;199(1):118-126.

68. Prieto-González S, Espígol-Frigolé G, García-Martínez A, et al. The expanding role of imaging in systemic vasculitis. Rheum Dis Clin North Am. 2016;42(4):733-751.

69. Nielsen BD, Hansen IT, Kramer S, et al. Simple dichotomous assessment of cranial artery inflammation by conventional 18F-FDG PET/ CT shows high accuracy for the diagnosis of giant cell arteritis: a case-control study. Eur J Nucl Med Mol Imaging. 2019;46 (1):184-193.

70. Nienhuis PH, Sandovici M, Glaudemans AWJM, Slart RHJA, Brouwer E. Visual and semiquantitative assessment of cranial artery inflammation with FDG-PET/CT in giant cell arteritis. Semin Arthritis Rheum. 2020;50(4):616-623.

71. Blockmans D. Ceuninck L de, Vanderschueren S, Knockaert D, Mortelmans L, Bobbaers H. Repetitive 18F-fluorodeoxyglucose positron emission tomography in giant cell arteritis: a prospective study of 35 patients. Arthritis Care Res (Hoboken). 2006;55(1):131-137.

72. Nielsen BD, Gormsen LC, Hansen IT, Keller KK, Therkildsen P, Hauge E-M. Three days of high-dose glucocorticoid treatment attenuates large-vessel 18F-FDG uptake in large-vessel giant cell arteritis but with a limited impact on diagnostic accuracy. Eur J Nucl Med Mol Imaging. 2018;45(7):1119-1128.

73. Clifford AH, Murphy EM, Burrell SC, et al. Positron emission tomography/computerized tomography in newly diagnosed patients with giant cell arteritis who are taking glucocorticoids. J Rheumatol. 2017;44(12):1859-1866.

74. Robson JC, Kiran A, Maskell J, et al. The relative risk of aortic aneurysm in patients with giant cell arteritis compared with the general population of the UK. Ann Rheum Dis. 2015;74(1):129-135.

75. Blockmans D, Coudyzer W, Vanderschueren S, et al. Relationship between fluorodeoxyglucose uptake in the large vessels and late aortic diameter in giant cell arteritis. Rheumatology. 2008;47 (8):1179-1184.
76. de Boysson H, Liozon E, Lambert M, et al. 18F-fluorodeoxyglucose positron emission tomography and the risk of subsequent aortic complications in giant-cell arteritis: a multicenter cohort of 130 patients. Medicine (Baltimore). 2016;95(26):e3851.

77. Muratore F, Crescentini F, Spaggiari L, et al. Aortic dilatation in patients with large vessel vasculitis: A longitudinal case control study using PET/CT. Semin Arthritis Rheum. 2019;48(6):1074-1082.

78. Ihata A, Shizukuishi K, Kishimoto D, et al. FRI0476 Relative fdg accumulation of the aortic wall lesions to aortic blood pool in $18 \mathrm{f}$-fdg-pet and pet/ct is a useful parameter for assessing the disease activity of takayasu arteritis. Ann Rheum Dis. 2013;72(Suppl 3): A536-A536.

79. Sharma V, Nagaraj S, Mangat G, Balakrishnan C, Krishna B, Samant R. AB0778 Role of pet scan in the management of patients with takayasu arteritis. Ann Rheum Dis. 2013;71(Suppl 3):683.

80. Alibaz-Oner F, Dede F, Ones T, Turoglu HT, Direskeneli H. Patients with Takayasu's arteritis having persistent acute-phase response usually have an increased major vessel uptake by $18 \mathrm{~F}$-FDG-PET /CT. Mod Rheumatol. 2015;25(5):752-755.

81. Santhosh S, Mittal BR, Gayana S, Bhattacharya A, Sharma A, Jain S. F-18 FDG PET/CT in the evaluation of Takayasu arteritis: an experience from the tropics. J Nucl Cardiol. 2014;21(5):993-1000.

82. Lee K, Cho A, Choi Y, et al. The role of 18F-fluorodeoxyglucosepositron emission tomography in the assessment of disease activity in patients with Takayasu arteritis. Arthritis Rheum. 2012;64 (3):866-875.

83. Incerti E, Tombetti E, Fallanca F, et al. 18 F-FDG PET reveals unique features of large vessel inflammation in patients with Takayasu's arteritis. Eur J Nucl Med Mol Imaging. 2017;44(7):1109-1118.

84. Derdelinckx I, Maes A, Bogaert J, Mortelmans L, Blockmans D. Positron emission tomography scan in the diagnosis and follow-up of aortitis of the thoracic aorta. Acta Cardiol. 2000;55(3):193-195.

85. Drieskens O, Blockmans D, Van den Bruel A, Mortelmans L. Riedel's thyroiditis and retroperitoneal fibrosis in multifocal fibrosclerosis: positron emission tomographic findings. Clin Nucl Med. 2002;27(6):413-415.

86. Blockmans D, Baeyens H, Van Loon R, Lauwers G, Bobbaers H. Periaortitis and aortic dissection due to Wegener's granulomatosis. Clin Rheumatol. 2000;19(2):161-164.

87. Salvarani C, Pipitone N, Versari A, et al. Positron emission tomography (PET): evaluation of chronic periaortitis. Arthritis Care Res (Hoboken). 2005;53(2):298-303.

88. Hotta M, Naka G, Minamimoto R, Takeda Y, Nivolumab-Induced Periaortitis HM. Demonstrated by FDG PET/CT. Clin Nucl Med. 2020;45(11):910-912.

89. Zhang J, Chen H, Ma Y, et al. Characterizing IgG4-related disease with 18 F-FDG PET/CT: a prospective cohort study. Eur J Nucl Med Mol Imaging. 2014;41(8):1624-1634.

90. Šteňová E, Šteňo B, Povinec P, Ondriaš F, Rampalová J. FDG-PET in the Erdheim-Chester disease: its diagnostic and follow-up role. Rheumatol Int. 2012;32(3):675-678.

91. Young JR, Johnson GB, Murphy RC, Go RS, Broski SM. 18F-FDG PET/CT in Erdheim-Chester Disease: imaging Findings and Potential BRAF Mutation Biomarker. J Nucl Med. 2018;59(5):774-779.

92. Nakatani K, Nakamoto Y, Togashi K. Utility of FDG PET/CT in IgG4-related systemic disease. Clin Radiol. 2012;67(4):297-305. 


\section{Publish your work in this journal}

Open Access Rheumatology Research and Reviews is an international, peer-reviewed, open access journal publishing original research, reports, editorials, reviews and commentaries on all aspects of clinical and experimental rheumatology in the clinic and laboratory including the following topics: Pathology, pathophysiology of rheumatological diseases; Investigation, treatment and management of rheumatological diseases; Clinical trials and novel pharmacological approaches for the treatment of rheumatological disorders. The manuscript management system is completely online and includes a very quick and fair peer-review system, which is all easy to use. Visit http://www.dovepress.com/testimonials.php to read real quotes from published authors. 